\title{
Value-at-Risk and Minimum Variance in the Investment Portfolio with Non Constant Volatility
}

\author{
Sukono, E. Lesmana, D. Johansyah, H. Napitupulu, Y. Hidayat, Diana Purwandari
}

\begin{abstract}
One of the criteria for efficient portofilio is that it produces the same level of profit, but with minimum risk.This paper discusses the estimates Value-at-Risk and minimum variance on an investment portfolio.In this case it is assumed that the asset return follows the time series model. Therefore, non-constant meanis estimated using autoregressive moving average (ARMA) models. While non constant volatility is estimated using generalized autoregressive conditionaly heteroscedasticity (GARCH) models. To determine the minimum variance is done using Markowitz's model optimization. Furthermore, Value-at-Risk is calculated based on the values of the mean and minimum variance. The result of return analysis of assets of BBRI, INCI, LPBN, and MPPA, obtained the minimum variance value of 0.011734775 , and at the $95 \%$ confidence level obtained Value-at-Risk of 0.017873889.The minimum variance and Value-at-Risk are obtained on the vector of the investment weighted composition as $\mathrm{X}^{\prime}=(0.092827551$, $0.212180907,0.14631804,0.548673502)$. So to get a minimum risk on the investment portfolio consisting of the four assets, the capital allocation must follow the vector of weighted composition produced.
\end{abstract}

Index Terms: asset return, time series, mean model, variance model, Markowitz's model.

\section{INTRODUCTION}

Today successful businessman, in every decision making, are never free of risk considerations, so that the decisions are made not based on speculation only. Risk is measured based on the unexpected profitability of an investment [8; 19].The greater the deviation from unexpected profits of an investment, is the greater the risk $[1 ; 21]$. Returns and risks are in the same direction, the greater the expected return, usually followed by an increased risk. Conversely, the smaller the risk faced, is the smaller the expected return [19]. Risks can usually be reduced by investing in more than one type of investment (stock), or often referred to as an investment portfolio. This is done with the aim of obtaining

Revised Manuscript Received on April 25, 2019.

Sukono, Department of Mathematics, Faculty of Mathematics and Natural Sciences, Universitas Padjadjaran, Indonesia.

E. Lesmana, Department of Mathematics, Faculty of Mathematics and Natural Sciences, Universitas Padjadjaran, Indonesia.

D. Johansyah, Department of Mathematics, Faculty of Mathematics and Natural Sciences, Universitas Padjadjaran, Indonesia.

H. Napitupulu, Department of Mathematics, Faculty of Mathematics and Natural Sciences, Universitas Padjadjaran, Indonesia.

Y. Hidayat, Department of Mathematics, Faculty of Mathematics and Natural Sciences, Universitas Padjadjaran, Indonesia.

Diana Purwandari, Department of Mining, Faculty of Engineering, Universitas Muhammadiyah Tasikmalaya, Indonesia. certain benefits with a minimum risk, or by a certain level of risk the maximum profit can be obtained [3;20]. By stock selection and appropriate proportion of fund allocation, portfolio risk can be reduced to a minimum level [13]. Although the word risk is often used in the business world, but there are still many businessman who still have difficulty on how to measure it.Many methods of measuring risk, one of which is popular today, that is Value-at-Risk(VaR) [4; 22].

On individual stocks, according to Angelovska [1] and Kuester et al. [9], the measure of Value-at-Risk is strongly influenced by two parameters, namely the mean and volatility parameters (standard deviation). Referring to Tsay [23], Sukono et al. [18], and Soeryanan et al. [14; 15; 16] the mean and volatility parameters are often non-constant as time changes. Such parameters can be estimated using time series model. The non-constant mean parameter, referring to Atsmegiorgis et al. [2], can be estimated using the autoregressive moving average (ARMA) model. Furthermore, when referring to Stancu [17], the volatility parameters of non-constant volatility can be estimated using models of generalized autoregressive conditional heteroscedasticity (GARCH).In the stock portfolio, the Value-at-Risk measure is influenced by the parameters of mean and variance ofthe portfolio. The mean and variance of this portfolio is strongly influenced by the proportion (weighting) of the allocation of funds in the creation of an efficient portfolio.To determine the weight in the formation of efficient portfolio is done by using optimization techniques.Qin [9], Gambrah \& Pirvu [6], and Cevizci [5], optimized the investment portfolio using the mean-variance portfolio model approach. The purpose of such optimization is to determine the weight of the allocation of funds to construct an efficient portfolio [19].Furthermore, the problem is how much the value of risk on the optimum portfolio that will be faced by entrepreneurs, in an investment portfolio in which consist of several stocks.

Therefore, based on the above problems, risk values estimation is done in this paper, whether measured using variance as well as measured using Value-at-Risk, to construct an optimum portfolio. The parameters required in optimum portfolio formation are estimated using time series model approach. The goal is to determine the value of risk and expectation return on the optimum portfolio, if the analyzed stock return data are following the time series pattern. This approach method is then applied to the analysis of several stocks traded on the

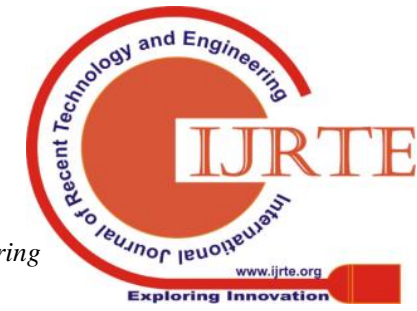


Indonesian capital market. With purpose that the results of this study can provide knowledge for the entrepreneurs in conducting investment portfolio.

\section{METHODOLOGY}

In this methodology section, it is discussed respectively the models used in data analysis, including: stock return, mean model in time series, volatility model in time series, Value-at-Risk model, and investment portfolio models.

\section{A. Stocks Return}

In this section, the model of determining stock return is discussed. Consider that the stock price in time $t$ is $R_{t}$. In the analysis of financial data, the value of stock return $Z_{t}$ determined based on continously compound return or return which is formulated as:

$Z_{t}=\ln \left(\frac{R_{t}}{R_{t-1}}\right)$,

where $t=1,2, \ldots, T$ with $T$ the number of data, and it is assumed that $R_{0}=1$ [23]. The return data that has been determined based on equation (1), then used for the analysis of the following modeling.

\section{B. Mean Models In Time Series}

This section deals with the mean model in time series. Consider $Z_{t}$ stock return at time $t$, mean model in time series data can be estimated using the equation Autoregressive Moving Average, $\operatorname{ARMA}(p, q)$, yang persamaannya dinyatakan sebagai $[18 ; 23]$ :

$$
Z_{t}=\omega_{0}+\sum_{i=1}^{p} \varphi_{i} Z_{t-i}+u_{t}-\sum_{j=1}^{q} \delta_{j} u_{t-j},
$$

with $\left\{u_{t}\right\}$ is the residual sequence that is assumed to have normal white noise distribution, which has mean 0 and variance $\sigma_{a}^{2}$. Value of $p$ and $q$ is a non-negative number, which is the order of ARMA model. Model AR and MA adalah bentuk khusus dari model $\operatorname{ARMA}(p, q)$.

\section{1) Steps In Modeling Mean In Time Series}

In summary, the mean modeling steps in the time series respectively are as follows: (i) Stationarity test of data return; (ii) Identification of the tentative model, that is determining the order $p$ and $q$ based on the autocorrelation function (ACF) and partial autocorrelation function (PACF) plot; (iii) Estimation of parameters, can be done using maximum likelihood estimator method; (iv) Verification and validation test of the mean model estimator; and (v) If the model is significant, it can be used recursively [18; 23].

\section{Volatility Models In Time Series}

This section the discussion is about the volatility model in time series. Autoregressive conditional heteroscedasticity $(\mathrm{ARCH})$ model was introduced by Engle in 1982.ARCH model is a squared residuals autoregressive process of mean model. In ARCH $(m)$ model, it is assumed that return $Z_{1}, Z_{2}, \ldots$ described as process $[8 ; 23]$ :

$$
\begin{aligned}
Z_{t} & =\mu_{t}+u_{t}, u_{t}=\sigma_{t} \varepsilon_{t}, \\
\text { and } \sigma_{t}^{2} & =\beta_{0}+\sum_{i=1}^{m} \beta_{i} u_{t-i}^{2}+\varepsilon_{t},
\end{aligned}
$$

where $\mu_{t}$ is the expectation of $Z_{t}, \sigma_{t}^{2}$ is the variance of $Z_{t}$, and $\varepsilon_{t}$ is the random residual with mean 0 and variance 1. It is assumed that $\left\{\varepsilon_{t}\right\} \sim$ iid $N(0,1), \beta_{0}$ and $\beta_{i}$ is a constant, $\beta_{0}>0$, and $\beta_{i} \geq 0, i=1, \ldots, m$.

\section{1) Detection test of ARCH effects existence}

To detect the existence of ARCH effect, the Lagrange-Multiplier (LM) test is performed. The LM statistical test was introduced by Engle in 1982. Tests for the detection of $\operatorname{ARCH}(p)$ effects existence performed by hypotesis $\quad H_{0}: \quad \beta_{0}=\beta_{1}=\ldots=\beta_{m}=0 \quad$ against alternative $H_{1}: \exists \beta_{0} \neq \beta_{1} \neq \ldots \neq \beta_{m} \neq 0$ [17;23].

This LM statistic shows asymptotically equivalent to statistic $T \times R^{2}$, where $T$ is the sample size $R^{2}$ calculated from time series regression: $u_{t}^{2}=a_{0}+a_{1} u_{t-1}^{2}+\ldots+a_{m} u_{t-m}^{2}+\varepsilon_{t}[20 ; 23]$.

Where hipotesis $H_{0}$ : has no $\mathrm{ARCH}$ effect, against alternative $H_{1}$ : has ARCH effect. LM statistics and $T \times R^{2}$ asymptotically $\chi^{2}(p)$ distributed. As an alternative form of detection test ARCH effect existence, can be done by using portmanteau test, otherwise known as Ljung and Box statistical test for $\varepsilon_{t}[23]$.

Models of generalized authoregresive conditional heteroscedasticity (GARCH); was introduced by Bollerslev in 1986.The GARCH model is a general form or generalization of the ARCH model. GARCH $(m, n)$ model generally can be expressed by following equations $[2 ; 23]$ :

$$
\begin{aligned}
& u_{t}=\sigma_{t} \varepsilon_{t}, \\
& \sigma_{t}^{2}=\beta_{0}+\sum_{i=1}^{m} \beta_{i} u_{t-i}^{2}+\sum_{j=1}^{n} \alpha_{j} \sigma_{t-j}^{2}+\varepsilon_{t}
\end{aligned}
$$

Refer to equation (3) and equation (4), the conditional expectation and variance of $\varepsilon_{t}$ is:

$$
\begin{aligned}
& E\left(\varepsilon_{t} \mid F_{t-1}\right)=0 \text { and } \\
& \operatorname{Var}\left(\varepsilon_{t} \mid F_{t-1}\right)=E\left(\varepsilon_{t}^{2} \mid F_{t-1}\right)=\sigma_{\varepsilon}^{2}
\end{aligned}
$$

\section{2) Steps on modelling volatility in time series}

Respectively, the steps of volatility modelling in time series are as follows: (i) Estimation of the mean model in time series (e.g. ARMA model);(ii) Use the residual of the mean model as test detection of the ARCH effect existence; (iii) If there is an ARCH effect, 
identify the volatility model and estimates it simultaneously with the mean and volatility models; (iv) Perform a verification and validation tests to test the fitness of the model; and (v) If the model is fit, use it as predictions recursively $[18 ; 23]$.

\section{Value-at-Risk Model}

In this section the Value-at-Risk model as a measure of risk is discussed. Consider the portfolio consisting of multiple stocks. Generally, it is assumed that stock returns are normally univariate distributed which has two parameters, that are mean $\mu$, and standard deviation $\sigma$. Estimate Value-at-Risk is the determination of the $(1-\alpha) \%$, percentile of the standard normal distribution $t_{1-\alpha}[4 ; 8]$ :

$$
\begin{aligned}
1-\alpha=\int_{-\infty}^{\kappa} f(z) d z & =\int_{-\infty}^{t_{1-\alpha}} \Phi(t) d t=N\left(t_{1-\alpha}\right), \text { with } \\
\text { quartile } \kappa & =t_{1-\alpha} \sigma+\mu,
\end{aligned}
$$

where $\Phi(z)$ is the standard normal density distribution function, $N(z)$ is the normal cumulative distribution, $Z$ is the random variable of stocks return with value $z, f(z)$ is the normal distribution density function of the stock return, with mean $\mu$ and standard deviation $\sigma$, with $\kappa$ smallest return if the given level of confidence $\alpha$.

Estimatted Value-at-Risk $(V a R)$ can be perfoemed by equation:

$$
\operatorname{VaR}=-W_{0} \times \kappa=-W_{0}\left(t_{1-\alpha} \sigma+\mu\right),
$$

with $W_{0}$ is an initial modal and minus sign (-) represents a loss [8].

\section{E. Investment Portfolio Models}

Suppose that $N$ stocks, and return of each stocks given by random variable $Z_{1 t}, \ldots, Z_{N t}$. If a businessman establishes a portfolio with weighted vectors: $\mathbf{x}^{\prime}=\left(x_{1}, \ldots, x_{N}\right)$ with $\mathbf{x}^{\prime} \mathbf{e}=1$, where $\mathbf{e}^{\prime}=(1, \ldots, 1)$, then, the portfolio return is given by random variable:

$$
Z_{p}=\sum_{i=1}^{N} x_{i} Z_{i}=\mathbf{x}^{\prime} \mathbf{Z}
$$

where $\mathbf{Z}^{\prime}=\left(Z_{1 i}, \ldots, Z_{N t}\right)$. The expectation value of equation (8) is given by:

$$
\mu_{p}=E\left[Z_{p}\right]=\sum_{i=1}^{N} x_{i} \mu_{i}=\mathbf{x}^{\prime} \boldsymbol{\mu}
$$

where $\boldsymbol{\mu}^{\prime}=\left(\mu_{1}, \ldots, \mu_{N}\right)$ with $\mu_{i}=E\left[Z_{i t}\right]$ and $i=1, \ldots, N$ , While the portfolio variance is given by:

$\sigma_{p}^{2}=\operatorname{Var}\left[Z_{p}\right]=\sum_{i}^{N} \sum_{j=1}^{N} x_{i} x_{j} \operatorname{Cov}\left(Z_{i t}, Z_{j t}\right)=\mathbf{x}^{\prime} \Lambda \mathbf{x}$,

where $\boldsymbol{\Lambda}=\left(\sigma_{i j}\right)$ is the variance-covariance matrix, with $\sigma_{i j}=\operatorname{Cov}\left(Z_{i t}, Z_{j t}\right)[7 ; 19]$.

\section{1) Portofolio Eficient.}

Consider $\mathbf{x}$ indicate a the weighted vector on the efficient portfolio. To determine the values of vector $\mathbf{x}$, Lagrange Multiplier equation is arranged as:

$L\left(\mathbf{x}, \eta_{1}, \eta_{2}\right)=\mathbf{x}^{\prime} \boldsymbol{\Lambda} \mathbf{x}+\eta_{1}\left(\mu_{p}-\mathbf{x}^{\prime} \boldsymbol{\mu}\right)+\eta_{2}\left(1-\mathbf{x}^{\prime} \mathbf{e}\right)$,

where $\eta_{1}$ and $\eta_{2}$ is the Lagrange multiplier. To find the solution of equation (11) is done by differentiate it respect to weight vector $\mathbf{X}$ as:

$\frac{\partial}{\partial \mathbf{x}} L\left(\mathbf{x}, \eta_{1}, \eta_{2}\right)=2 \Lambda \mathbf{x}-\eta_{1} \mathbf{x}-\eta_{2} \mathbf{e}=0$,

According to Ruppert [12], a matrix $\boldsymbol{\Lambda}$ with order $n \times n$ and vector $\mathbf{X}$ with dimension $n \times 1$, it is applied that:

$$
\frac{\partial}{\partial \mathbf{x}}\left(\mathbf{x}^{\prime} \boldsymbol{\Lambda} \mathbf{x}\right)=\left(\boldsymbol{\Lambda}+\boldsymbol{\Lambda}^{\prime}\right) \mathbf{x}
$$

Thus the solution of equation (12) is:

$\mathbf{x}=\frac{1}{2} \boldsymbol{\Lambda}^{-1}\left(\eta_{1} \boldsymbol{\mu}+\eta_{2} \mathbf{e}\right)=\boldsymbol{\Lambda}^{-1}\left(\lambda_{1} \boldsymbol{\mu}+\lambda_{2} \mathbf{e}\right)$,

where $\lambda_{1}=\frac{1}{2} \eta_{1}$ and $\lambda_{2}=\frac{1}{2} \eta_{2}$ are the new Lagrange multiplier. Thus, if the equation (13) is distributed into equation (9) and into equation $\mathbf{x}^{\prime} \mathbf{e}=1$, the following system of equations is obtained [12]:

$$
\mu_{p}=\boldsymbol{\mu}^{\prime} \mathbf{x}=\lambda_{1} \boldsymbol{\mu}^{\prime} \boldsymbol{\Lambda}^{-1} \boldsymbol{\mu}+\lambda_{2} \boldsymbol{\mu}^{\prime} \boldsymbol{\Lambda}^{-1} \mathbf{e},
$$

and $1=\mathbf{e}^{\prime} \mathbf{x}=\lambda_{1} \mathbf{e}^{\prime} \boldsymbol{\Lambda}^{-1} \boldsymbol{\mu}+\lambda_{2} \mathbf{e}^{\prime} \boldsymbol{\Lambda}^{-1} \mathbf{e}$

As simplification, suppose that $A=\boldsymbol{\mu}^{\prime} \boldsymbol{\Lambda}^{-1} \boldsymbol{\mu}$ $B=\boldsymbol{\mu}^{\prime} \boldsymbol{\Lambda}^{-1} \mathbf{e}=\mathbf{e}^{\prime} \boldsymbol{\Lambda}^{-1} \boldsymbol{\mu}$, and $C=\mathbf{e}^{\prime} \boldsymbol{\Lambda}^{-1} \mathbf{e}$, such that the system of equations (14) and (15), become:

$$
\mu_{p}=\boldsymbol{\mu}^{\prime} \mathbf{x}=\lambda_{1} A+\lambda_{2} B
$$

And $1=\mathbf{e}^{\prime} \mathbf{x}=\lambda_{1} B+\lambda_{2} C$.

For the solution of equations (16) and (17), $\lambda_{1}$ and $\lambda_{2}$ are obtained as follows:

$\lambda_{1}=\frac{C \mu_{p}-B}{A C-B^{2}}$, and $\lambda_{2}=\frac{A-B \mu_{p}}{A C-B^{2}}$.

If Equation (18) substitutes into equation (13), the efficient weighted portfolio vector is obtained as:

$$
\begin{aligned}
\mathbf{x} & =\frac{C \mu_{p}-B}{A C-B^{2}} \Lambda^{-1} \boldsymbol{\mu}+\frac{A-B \mu_{p}}{A C-B^{2}} \Lambda^{-1} \mathbf{e}=\frac{A \Lambda^{-1} \mathbf{e}-B \Lambda^{-1} \boldsymbol{\mu}}{A C-B^{2}}+\frac{C \Lambda^{-1} \boldsymbol{\mu}-B \Lambda^{-1} \mathbf{e}}{A C-B^{2}} \mu_{p} \\
& =\mathbf{g}+\mathbf{h} \mu_{p},
\end{aligned}
$$

where $\mathbf{g}=\frac{A \boldsymbol{\Lambda}^{-1} \mathbf{e}-B \boldsymbol{\Lambda}^{-1} \boldsymbol{\mu}}{A C-B^{2}}$ dan $\mathbf{h}=\frac{C \boldsymbol{\Lambda}^{-1} \boldsymbol{\mu}-B \boldsymbol{\Lambda}^{-1} \mathbf{e}}{A C-B^{2}}$. $\mathbf{g}$ and $\mathbf{h}$ are the known vectors, and not depend of $\mu_{p}$ [12]. 
The target of desired portfolio return $\mu_{p}$ may be varied over several values in the interval:

$$
\mu_{p}^{M i n} \leq \mu_{p} \leq \mu_{p}^{M a x}
$$

Based on the variation value of $\mu_{p}$ in the interval (20), the vector weight efficient portfolio $\mathbf{X}$ can be obtained in which refer to the equation (19).

\section{2) Portfolio with minimum variance}

To determine the value of $\mu_{p}^{M i n}$ can be done by optimization on the portfolio with minimum variance. Based on the weight vector in equation (19), the variance of equation (10) can be expressed as:

$$
\begin{aligned}
& \sigma_{p}^{2}=\operatorname{Var}\left(\mu_{p}^{M i n}\right)=\left(\mathbf{g}+\mathbf{h} \mu_{p}^{M i n}\right)^{\prime} \mathbf{\Lambda}\left(\mathbf{g}+\mathbf{h} \mu_{p}^{M i n}\right) \\
& =\mathbf{g}^{\prime} \mathbf{\Lambda} \mathbf{g}+2 \mathbf{g}^{\prime} \boldsymbol{\Lambda} \mathbf{h} \mu_{p}^{M i n}+\mathbf{h}^{\prime} \boldsymbol{\Lambda} \mathbf{h} \mu_{p}^{M i n}
\end{aligned}
$$

To determine the minimum variance in the investment portfolio, equation (21) can be diferentiate respect to $\mu_{p}^{M i n}$ and make it equal to zero, as follows:

$\frac{d}{d \mu_{p}^{M i n}} \operatorname{Var}\left(\mu_{p}^{M i n}\right)=2 \mathbf{g}^{\prime} \mathbf{\Lambda h}+2 \mathbf{h}^{\prime} \mathbf{\Lambda} \mathbf{h} \mu_{p}^{M i n}=0$.

Solving equation (22)can be obtained the value of $\mu_{p}^{M i n}$ as follows [12]:

$$
\mu_{p}^{M i n}=-\frac{\mathbf{g}^{\prime} \mathbf{\Lambda} \mathbf{h}}{\mathbf{h}^{\prime} \mathbf{\Lambda} \mathbf{h}}
$$

While to determine the value of $\mu_{p}^{M a x}$, is depend on the applicable rules of stock trading system. If the short sales are allowed the value of $\mu_{p}^{M a x}$ is relatively unlimited. But, ifthe short sales are not allowed, then the value of $\mu_{p}^{M a x}$ can be determined based on the requirements that weighted vector $\mathbf{X}>0$, such that by referring to equation (19) $\mathbf{g}+\mathbf{h} \mu_{p}^{\operatorname{Max}}>0$ is obtained [19]. Furthermore, if the left and right hand side of that inequality are multiplied by $\mathbf{g}^{\prime} \boldsymbol{\Lambda}$, then, it is obtained that

$$
\begin{aligned}
& \mathbf{g}^{\prime} \mathbf{\Lambda} \mathbf{g}+\mathbf{g}^{\prime} \mathbf{\Lambda} \mathbf{h} \mu_{p}^{M a x}>0 \text { or } \mu_{p}^{M a x}>-\frac{\mathbf{g}^{\prime} \mathbf{\Lambda} \mathbf{g}}{\mathbf{g}^{\prime} \mathbf{\Lambda} \mathbf{h}} \text { or } \\
& \mu_{p}^{M a x} \leq-\frac{\mathbf{g}^{\prime} \mathbf{\Lambda} \mathbf{g}}{\mathbf{g}^{\prime} \mathbf{\Lambda} \mathbf{h}}+\xi,
\end{aligned}
$$

where $\xi$ is a relatively small number, such that it makes the weighted vector $\mathbf{X}>0$.

Furthermore, the formulas described in the previous-mentioned methodology are used to analyze data from several stocks.

\section{RESULT AND DISCUSSION}

In this section, the discussion is about the data analysis performed referring to the methodology described in Section 2. Discussion includes the analysed data, mean and volatility modelling in time series, investment portfolio optimization, and discussion.

\section{A. The Analyzed Data}

The data analysed in this paper is the daily stock prices of four companies, which consists of BBRI, INCI, LPBN, and MPPA, which is accessed through http://www.finance.go.id//. The observed stocks data is the closing rice during the period of May 20, 2011 until May 20, 2018, which consists of five working days of the week except holidays. The number of data obtained respectively, are given in Table 1. The return of stocks price data is then determined by using equation (1).

\section{B. Mean And Volatility Modeling In Time Series}

In this section we analyse the modelling of mean and volatility in time series refer to section 2.2. and section 2.3.In summary, the modelling is done with the following stages.

\section{1) Mean modeling in time series.}

Firstly, the stationarity test is done by using statistics Augmented Dickey Fuller (ADF) to the stocks return data determined by equation (1). The test results show that the return of the four stocks analysed, is stationary at the level of significance $\alpha=5 \%$. Secondly, the identification of mean model is done by using the correlogram stock return data. Based on the ACF and PACF of the correlogram, the averaging tentative model was determined: ARMA $(1,1), \mathrm{AR}$ (2), AR (1), and AR (2). Thirdly, based on the tentative models, the estimation of model parameters are referring to equation (2).Fourth, verification and validation test are done to the obtained model parameter estimator. Based on verification and validation test results, it is shown that ARMA (1.1), AR (2), AR (1), and AR (2) models are significant for the next process, that is volatility modelling in time series.

\section{2) Modelling volatility in time series.}

Firstly, according to the residuals of the mean model, the test of ARCH element existence is conducted by refer to section 2.3, and the results show that the four stocks return have the ARCH effect. Secondly, using data from the squared residuals of mean model the identification of volatility models is done. The correlogram is used to identify the volatility model. Based on the ACF and PACF of the correlogram the tentative of volatility models are defined respectively as: $\operatorname{GARCH}(1,1) ; \operatorname{ARCH}(1,1) ; \operatorname{GARCH}(1,1)$; and GARCH $(1,1)$. Thirdly, based on the volatility tentative model, the estimation of volatility model parameters with reference to the equation (3) is done. The estimates are performed simultaneously with mean model, and its results are given in Table 1, column models. Fourthly, using the obtained estimator of model parameter, the verification and validation test are done. Based on the

$$
\text { y and Engin }
$$


results of verification and validation tests, it is shows that the mean and volatility models are significant.

Estimators of the generated mean and volatility models are then used to predict one period ahead, and the predicted results are given in Table 1 , column $\mu_{i}$ and $\sigma_{i}^{2}$.

Table 1.Estimator of mean model and volatility model

\begin{tabular}{cccccc}
\hline$i$ & Stocks & $\begin{array}{c}\text { Number } \\
\text { of Data }\end{array}$ & Models & $\mu_{i}$ & $\sigma_{i}^{2}$ \\
\hline 1 & BBRI & 1132 & ARMA(1,1)-GARCH(1,1)-M & 0.000298 & 0.001483 \\
2 & INCI & 1045 & AR(2)-TARCH(1,1) & 0.004638 & 0.000649 \\
3 & LPBN & 1030 & AR(1)-EGARCH(1,1) & 0.000584 & 0.000941 \\
4 & MPPA & 1080 & AR(2)-GARCH(1,1) & 0.000511 & 0.000251 \\
\hline
\end{tabular}

\section{Optimization Of Investment Portfolio}

Using data from Table 1 , in column $\mu_{i}$ can be formed the mean vector as $\boldsymbol{\mu}^{\prime}=(0.000298,0.004638,0.000584$, 0.000511 ). Furthermore, by using the data from Table 1, column $\sigma_{i}^{2}$ and values of covariance between stock returns, variance-covariance matrix, and inverse matrix can be formed as follows:

$$
\boldsymbol{\Lambda}=\left(\begin{array}{llll}
0.001483 & 0.000014 & 0.000007 & 0.000021 \\
0.000014 & 0.000649 & 0.000032 & 0.000009 \\
0.000007 & 0.000032 & 0.000941 & 0.000015 \\
0.000021 & 0.000009 & 0.000015 & 0.000251
\end{array}\right) ;
$$$$
\mathbf{\Lambda}^{-1}=10^{3} \times\left(\begin{array}{cccc}
0.6745 & -0.0143 & -0.0045 & -0.0046 \\
-0.0136 & 1.5444 & -0.0515 & -0.0522 \\
-0.0037 & -0.0516 & 1.0655 & -0.0618 \\
-0.0557 & -0.0511 & -0.0615 & 3.9900
\end{array}\right)
$$

Since there are four stocks analysed, then the vector $\mathbf{e}^{\prime}=(1,1$, $1,1)$ is defined to make the next calculation to be done.

By referring to equations (16) and (17), the obtained values respectively are $A=10.38400202, B=0.035186348$, and $C=7263.509$. Thus, using (19) the obtained vector respectively $\mathbf{g}^{\prime}=(0.146463855, \quad-0.135308012$, $0.182820855,0.806023303)$, and $\mathbf{h}^{\prime}=(-37.51275535$, $243.0306696,-25.52974505,-179.9881692)$. Thus by using (23) the minimum mean estimation $\mu_{p}^{M i n}=0.001429815$ is obtained and by using equation (19)the minimum portfolio weighted vector obtained as $\mathbf{x}^{\text {Min }}=(0.092827551$, $0.212180907,0.1431804,0.548673502)$. Therefore, by using equation (10) the estimation of minimum variance $\sigma_{p_{\text {Min }}}^{2}=$ 0.000137705 and the minimum volatility $\sigma_{p_{\text {Min }}}=$ 0.011734775 are obtained. Thus, if the level of significance $\alpha=95 \%$ is defined the percentile of normal standard distribution $t_{(1-95 \%)}=-1.645$ is obtained. So that if it is assumed that $W_{0}=1$ unit, then, by using equation (7) the Value-at-Risk $\operatorname{VaR}^{\mathrm{Min}}=0.0175873889$ is obtained.

For the maximum portfolio refer to equation (24), in this case the determined estimated maximum mean value $\mu_{p}^{M a x}=0.003900000$, and by using equation (19)the obtained maximum portfolio weighted vector $\mathbf{x}^{\text {Max }}=$ (0.000200000, $\quad 0.812500000, \quad 0.083300000$, $0.104100000)$. Therefore, by using equation (10) the maximum variance estimation $\sigma_{p_{M a x}}^{2}=0.000631807$ and the maximum volatility $\sigma_{p_{\text {Max }}}=0.025135771$ are obtained.Furthermore, if the defined level of significance is $\alpha=95 \%$, the percentile of normal standard distribution $t_{(1-95 \%)}=-1.645$ is obtained. Thus, if assumed that $W_{0}=1$ unit, then by using equation (7), the Value-at-Risk $\operatorname{VaR}^{\text {Max }}=0.037448344$ is obtained.

According to the calculation value, the efficient frontier of four stocks return portfolio analized is given as in Figure 1.

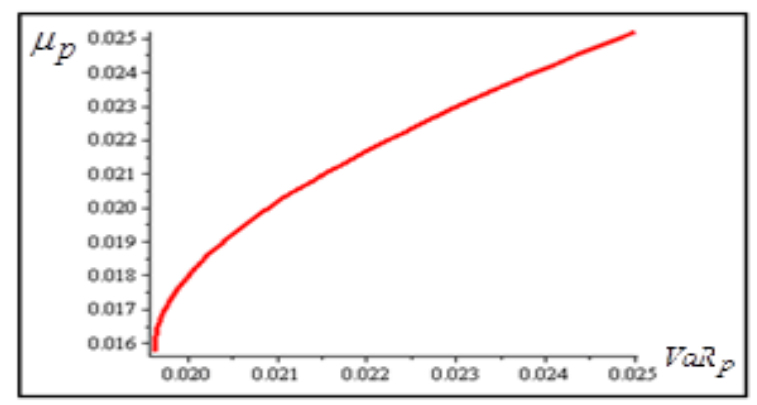

Fig.1. The surface of efficient portfolio four stocks returns

\section{Discussion}

In this section we discussed the results of the analysis that have been done in the previous sections. By observe the surface of efficient frontier curve in Figure 1, it is shown that the curve starts from the minimum point which is the pair of the minimum mean $\mu_{p}^{M i n}$ and minimum Value-at-Risk $\operatorname{VaR}^{\mathrm{Min}}$, that is the coordinate point $\left(\mu_{p}^{\mathrm{Min}}, \mathrm{VaR}^{\mathrm{Min}}\right)=$ $(0.001429815,0.0175873889)$.If short sales are not permitted, the efficient surface curve ends at the maximum point which is the pair of the maximum mean $\mu_{p}^{M a x}$ and maximum Value-at-Risk $\operatorname{VaR}^{M a x}$, that is the coordinate point $\left(\mu_{p}^{\operatorname{Max}}, \operatorname{VaR}^{\operatorname{Max}}\right)=(0.003900000$, 0.037448344). The minimum portfolio is achieved when the weight of the allocation of funds is $\mathbf{x}^{\text {Min }}=(0.092827551$, $0.212180907,0.1431804,0.548673502)$. Meanwhile, the maximum portfolio is achieved when the weight of the allocation of funds is $\mathbf{x}^{\operatorname{Max}}=(0.000200000,0.812500000$, $0.083300000,0.104100000)$.

Along with this efficient frontier curve, investors are eligible to invest, with the expectation target of the desired mean portfolio.Among the efficient frontier there is an optimal portfolio, and this optimal portfolio should be found. Every investor desiring the portfolio investment that can generate a big portfolio of mean return, but is expected to has a small level of risk. If it is assumed that the investors preferences are based on the expected returns and risks of the portfolio only, optimal portfolio selegtion can Bo, pherformed 
based on the efficient portfolio composition resulting in the ratio between mean $\mu_{p}$ and the biggest level of risk $V_{a} R_{p}$.

In the selection of investment portfolios, greatly influenced by the preferences of each businessman. The risk-seeking businessman will choose the portfolio with the smallest risk, so they will get a small return expectation. The risk conscious businessman, that will choose the expectation of maximum portfolio return, certainly will be accompanied by a large risk as well. Meanwhile, a rational businessman will choose a portfolio that has a ratio between the expectation returns and the risk of the largest portfolio.

\section{CONCLUSION}

In this paper we have analyzed the estimates of Value-at-Risk and minimum variance on an investment portfolio, by time series model approach. The analyzed data includes stocks: BBRI, INCI, LPBN, and MPPA. Based on the analysis the conclusion is as follows. Stocks return are respectively follow the models $\operatorname{ARMA}(1,1)$ - $\operatorname{GARCH}(1,1)$ $\mathrm{M} ; \operatorname{AR}(2)$ - TARCH$(1,1) ; \operatorname{AR}(1)-\operatorname{EGARCH}(1,1)$; and $\operatorname{AR}(2)$ - $\operatorname{GARCH}(1,1)$. The estimate model of time series is used to estimate the expected return and the variance of each stock. The estimator of the expected return and the variance of each stock are used to determine the minimum variance and Value-at-Risk. In the optimization on minimum portfolio, the estimator mean value 0.00142981 is obtained. The minimum portfolios are achieved when the weight of the modal allocation is as consecutively as given in vector $\mathbf{x}^{\mathrm{Min}}=$ (0.092827551, 0.212180907, 0.1431804, 0.548673502). Thus, the obtained value of a minimum variance is 0.000137705 , and with a significance level 95\%, Value-at-Risk 0.0178773889 is obtained. While in the maximum portfolio, the defined mean value estimator is 0.00469283 . The maximum portfolios are achieved when the weight of the capital allocation is as consecutively as given in vector $\mathbf{x}^{\operatorname{Max}}=(0.000200000,0.812500000,0.083300000$, $0.104100000)$. In the maximum portfolio, the obtained estimator value of maximum variance is 0.000631807 , and the significance level $95 \%$, the Value-at-Risk 0.037448344 is obtained. The results of this analysis are expected to be used as a consideration for investors who will invest in the four stocks previously mentioned.

\section{ACKNOWLEDGMENT}

Acknowledgments are conveyed to the Rector, Director of Directorate of Research, Community Involvement and Innovation, and the Dean of Faculty of Mathematics and Natural Sciences, Universitas Padjadjaran, with whomthe Internal Grant Program of Universitas Padjadjaran was made possible to, fund this research.The grant is a means of enhancing research and publication activities for researchers at Universitas Padjadjaran.

\section{REFERENCES}

1. J. Angelovska, "Managing Market Risk with VaR (Value at Risk)", Management, vol. 18, no. 2, pp. 81-96, 2013.
2. A. Atsmegiorgis, J. Kim, and S. Yoon, "The GARCH-GPD in Market Risks Modeling: An Empirical Exposition on KOSPI", Journal of the Korean Data \& Information Science Society, vol. 27, no. 6, pp. 1661-1671, 2016.

3. Y. Bansal, S. Kumar, and P. Verma, "Commodity Futures in Portfolio Diversification: Impact on Investor's Utility", Global Business and Management Research: An International Journal, vol. 6, no. 2, pp. $112-121,2014$.

4. K. Boudt, "Asset Allocation with Conditional Value-at-Risk Budgets", Journal of Risk, vol. 15, no. 3, pp. 39-68, 2013.

5. A. Cevizci, "A Comparison of Optimal Portfolio Performances of Three Optimization Methods", International Journal of Commerce and Finance, vol. 2, no. 1, pp. 137-146, 2016.

6. P.S.N. Gambrah, and T.A. Pirvu, "Risk Measures and Portfolio Optimization”, Journal Risk Financial Manag. vol. 7, pp. 113-129, 2014.

7. A.S. Hadi, A.A.E. Naggar, and M.N.A. Bary, "New Model and Method for Portfolios Selection", Applied Mathematical Sciences, vol. 10, no. 6, pp. $263-288,2016$.

8. E.S. Hasbullah, M. Suyudi, N.B.A. Halim, Sukono, F. Gustaf, and A.S. Putra, "A Comparative Study of Three Pillars System and Banking Methods in Accounting Long-Term Purposes of Retiree in Indonesian Saving Account”, IOP Conf. Series: Materials Science and Engineering, vol. 332, 2018.

9. K. Kuester, S. Mittnik, and M.S. Paolella, "Value-at-Risk Prediction: A Comparison of Alternative Strategies", Journal of Financial Econometrics, vol. 4, no. 1, pp. 53-89, 2006.

10. H. Napitupulu, Sukono, I.B. Mohd, Y. Hidayat, and S. Supian, "Steepest Descent Method Implementation on Unconstrained Optimization Problem Using C++ Program", IOP Conf. Series: Materials Science and Engineering, vol. 332, art. no. 012024, 2018.

11. Z. Qin, "Mean-Variance Model Fortfolio Optimization Problemin the Simultaneous Presenceof Randomand Uncertain Returns", European Journal of Operational Research, vol. 245, pp. 480-488, 2015.

12. D. Ruppert, Statistics and Finanace an Introduction, New York: Springer, 2004.

13. M. R. Sarker, "Markowitz Portfolio Model: Evidence from Dhaka Stock Exchange in Bangladesh", IOSR Journal of Business and Management, vol. 8 , no. 6 , pp. 68-73, 2013.

14. E. Soeryana, N. B. A. Halim, Sukono, E. Rusyaman, and S. Supian, "Mean-Variance Portfolio Optimization on Some Stocks by Using Non Constant Mean and Volatility Models Approaches", Proceedings of the International Conference on Industrial Engineering and Operations Management, Vol. 8-10 March 2016, pp. 3124-3131.

15. E. Soeryana, N. B.A. Halim, Sukono, E. Rusyaman, and S. Supian, "Mean-Variance Portfolio Optimization by Using Non Constant Mean and Volatility Based on the Negative Exponential Utility Function", AIP Conference Proceedings, vol. 1827, art. no. 020042, 2017.

16. E. Soeryana, N.B.A. Halim, Sukono, E. Rusyaman, and S. Supian, "Mean-Variance Portfolio Optimization by Using Time Series Approaches Based on Logarithmic Utility Function" IOP Conf. Series: Materials Science and Engineering, vol. 166, art. no. 012003, 2017.

17. S. Stancu, "Empirical Results of Modeling EUR/RON Exchange Rate Using ARCH, GARCH, EGARCH, TARCH and PARCH Models", Romanian Statistical Review, vol. 1, pp. 57-72, 2017.

18. Sukono, Y. Hidayat, Suhartono, B. Sutijo, A.T. Bon, and S. Supian, "Indonesian Financial Data Modeling and Forecasting By Using Econometrics Time Series and Neural Network", Global Journal of Pure and Applied Mathematics, vol. 12, no. 4, pp. 3745-3757, 2016.

19. S. Vaidyanathan, A.Sambas, S. Kacar and U. Cavusoglu. ”A New Finance Chaotic System, its Electronic Circuit Realization, Passivity based Synchronization and an Application to Voice Encryption." Nonlinear Engineering, vol. 8, no. 1, pp. 193-205, 2019

20. Sukono, E. Lesmana, D. Susanti, and H. Napitupulu, "Estimating the Value-at-Risk for Some Stocks at the Capital Market in Indonesia Based on ARMA-FIGARCH Models", IOP Conf. Series: Journal of Physics: Conf. Series, vol. 909, art. no. 012040, 2017.

21. Sukono, D. Susanti, M. Najmia, E. Lesmana, H. Napitupulu, A.S. Putra, and S. Supian, "Analysis of Stock Investment Selection Based on CAPM Using Covariance and Genetic Algorithm Approach", IOP Conf. Series: Materials Science and Engineering, vol. 332, art. no. 012046, 2018.

22. Sukono, Y. Hidayat, E. Lesmana, A.S. Putra, H. Napitupulu, and S Supian, "Portfolio Optimization by Using Linear Programing Models Based on Genetic Algorithm", IOP Conf. Series: Materials Science and Engineering, vol. 300, art. no. 012001, 2018.

23. R. S. Tsay, Analysis of Financial Time Series. Second Edition, Hoboken, New Jersey: John Wiley \& Sons, Inc., 2005. 